\title{
The combined effect of urban heat island and aerosols on clouds and light precipitation in mid-Korean peninsula in winter
}

\author{
SEUNG-HEE EUN, BYUN-GON KIM ${ }^{1}$
}

\begin{abstract}
${ }^{1}$ Department of atmopsheric environmental sciences, Gangneung-Wonju Nation University
\end{abstract}

Urban heat island effect and urban-induced aerosol affect cloud properties and precipitation by changing land cover and surface albedo and by interacting with clouds and meteorology. The individual effects of urbanization and aerosol on local or regional aspect have been examined separately in several modeling and observed analysis. It is important to investigate combined effect (urban heat island effect and aerosol effects) since it is not clear still in the quantitative understanding. To investigate the effects of urbanization and aerosol on clouds and precipitation in the mid-Korean peninsula, numerical simulations were conducted using the WRF for a case of light precipitation in winter. The simulated results for the urban heat island effect shows that urban heat island effect leads to rising temperature at 2 meter and reduced water vapor in urban area associated with the increased sensible heat. It results in the decrease of precipitation rate in urban region $(-40 \%)$ and near-down wind area $(-23 \%)$ because of the reduced liquid water path due to the dryness of UHI. Meanwhile, enhanced aerosols can change cloud microphysics such as cloud droplet radius decreases a maximum $40 \%$ and cloud droplet number concentration increases about 4 times in near-downwind and far-downwind of urban area, furthermore precipitation rate remarkably diminishes about $-16 \%$ in near-down wind region. The sensitivity experiment of combined effect was mostly similar to the results of the urbanization effect such as a decreased precipitation rate at urban area $(-38 \%)$. On the other hand, in the rural region, urban heat island effect and aerosol effect simultaneously lead to the decline of precipitation rate (max: $-25 \%$ ). In the future, it is necessary to analyze the aerosol effect regarding various spatial and temporal scales. 